\title{
School randomised trial on prevention of excessive weight gain by discouraging students from drinking sodas
}

\author{
Rosely Sichieri ${ }^{1, *}$, Ana Paula Trotte ${ }^{1}$, Rita Adriana de Souza ${ }^{1}$ and Gloria V Veiga ${ }^{2}$ \\ 'Department of Epidemiology, Institute of Social Medicine, State University of Rio de Janeiro, Rua São Francisco \\ Xavier, 524, $7^{\circ}$ andar, Bloco E. Cep 20550-012, Rio de Janeiro, R, Brazil: ${ }^{2}$ Department of Nutrition, Federal \\ University of Rio de Janeiro, Rio de Janeiro, RJ, Brazil
}

Submitted 9 October 2007: Accepted 3 April 2008: First published online 18 June 2008

\begin{abstract}
Objective: To determine whether an educational programme aimed at discouraging students from drinking sugar-sweetened beverages could prevent excessive weight gain.

Design: Forty-seven classes in twenty-two schools were randomised as intervention or control.

Subjects: Participants were 1140, 9-12-year-old fourth graders (435 in the intervention group and 608 in the control group). Sugar-sweetened beverages and juice intake were measured through one $24 \mathrm{~h}$ recall at baseline and another at the end of the trial. The main outcome was the change in BMI $(\mathrm{BMI}=$ weight $(\mathrm{kg}) / \mathrm{height}$ $\left(\mathrm{m}^{2}\right)$ ), measured at the beginning and at the end of the school year. Intentionto-treat analysis was performed taking into account the cluster (classes) effect.

Results: A statistically significant decrease in the daily consumption of carbonated drinks in the intervention compared to control (mean difference $=-56 \mathrm{ml} ; 95 \%$ CI $-119,-7 \mathrm{ml}$ ) was followed by a non-significant overall reduction in BMI, $P=0 \cdot 33$. However, among those students overweight at baseline, the intervention group showed greater BMI reduction $\left(-0.4 \mathrm{~kg} / \mathrm{m}^{2}\right.$ compared with $-0 \cdot 2 \mathrm{~kg} / \mathrm{m}^{2}$ in the control group $(P=0 \cdot 11)$ ), and this difference was statistically significant among girls $(P=0 \cdot 009)$. Fruit juice consumption was slightly increased in the intervention group $(P=0 \cdot 08)$, but not among girls.

Conclusion: Decreasing sugar-sweetened beverages intake significantly reduced BMI among overweight children, and mainly among girls. Efforts to reduce energy intake through liquids need to emphasise overall sweetened beverages and addition of sugar on juices.
\end{abstract}

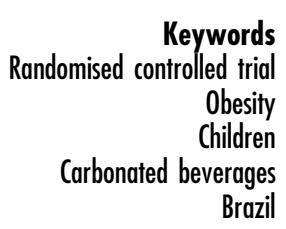

Obesity is a major public health problem in many countries throughout the world, especially for the young population and for the poor ${ }^{(1)}$. In Brazil, obesity and overweight have been increasingly common in adults ${ }^{(2)}$, as well as in adolescents ${ }^{(3)}$. Dietary interventions that could prevent excessive weight gain in adolescents are fundamental to curb this epidemic.

School is considered a suitable setting for the promotion of healthy lifestyles in children ${ }^{(4,5)}$. For obesity prevention many programmes have been tested among schoolchildren. Usually, these programmes have multiple focuses, including physical activity and nutritional behaviours, and most of them have attained good results in educating children on these issues ${ }^{(6,7)}$, but with little or no effect on weight change ${ }^{(7,8)}$. On the other hand, a randomised trial with British schoolchildren with a focus on reduction of carbonated sodas showed a statistically significant and clinically relevant reduction in the weight gain in the experimental group compared with controls ${ }^{(9)}$. The strategy for the study was to reduce overall energy intake by the substitution of sugar-sweetened beverages for non-caloric drinks. Several educational activities were employed in order to incorporate this message. Two other longitudinal studies conducted in the USA observed increased BMI and prevalence of overweight associated with sugar-sweetened beverages ${ }^{(10-12)}$, and a review of sugar-sweetened carbonated beverages linked their intake to weight gain in both children and adults $^{(13)}$.

Although some educators think that schools already have too much to do, and that prevention of obesity should not be expected to be an added responsibility ${ }^{(14)}$, school is considered an important part in the effort to prevent childhood obesity ${ }^{(15)}$. Also, in countries such as Brazil, public schools are one of the few public institutions that reach the majority in the low socio-economic groups. 
The result of the British study ${ }^{(9)}$ is particularly important for developing countries, since it was based only on sugar-sweetened carbonated beverages. The result of this intervention can be more appealing for public health programmes compared with the usually more successful school interventions, which are comprehensive in nature ${ }^{(8)}$ and harder to be implemented in most countries.

The aim of the present study was to determine whether a school-based intervention addressing the issue of a healthy lifestyle aimed at discouraging adolescents from drinking sugar-sweetened carbonated beverages could prevent excessive weight gain.

\section{Methods}

A cluster randomised controlled trial of fourth graders from twenty-two public schools in the metropolitan city of Niterói, Rio de Janeiro, Brazil, was conducted from March to December 2005. Most students in the public schools are from families of low socio-economic level. Children go to school either in the morning (08.00-12.00 hours) or in the afternoon (13.00-17.00 hours). Only morning classes were included in the study. Families of fourth grade children (most of them 10 and 11 years old) were informed of the study and only those children with informed consent given by the parents were included in the study, but all of them received information as well as baseball caps and water bottles with the campaign logo.

\section{Sample size}

Sample size was estimated based on data from a previous study conducted in the same geographical area, for which the standard deviation of sugar-sweetened beverages consumption was 1.49 cups per day. In order to detect a difference of 0.5 glass of sugar-sweetened beverages between the two groups with a power of $80 \%$ and a $5 \%$ significance level, the sample size needed to be of 140 children in each arm of the trial. This sample size would also allow the detection of a difference of about 1 unit in BMI. Due to the cluster design (classes) and anticipating a rate of parental agreement of around $80 \%$, the sample size was set at 600 students. Since the school principals did not agree to select only one class of fourth graders, all classes were included, increasing the sample size to 1166 children, in forty-seven classes from twenty-two schools (Fig. 1). Schools, instead of classes, were randomised to reduce contamination of the intervention. We began the study by ranking schools based on the prevalence of overweight and of obesity, and randomisation was generated by blocking of four schools. The last two in the list were randomly assigned to intervention or control groups, balancing the groups by BMI.

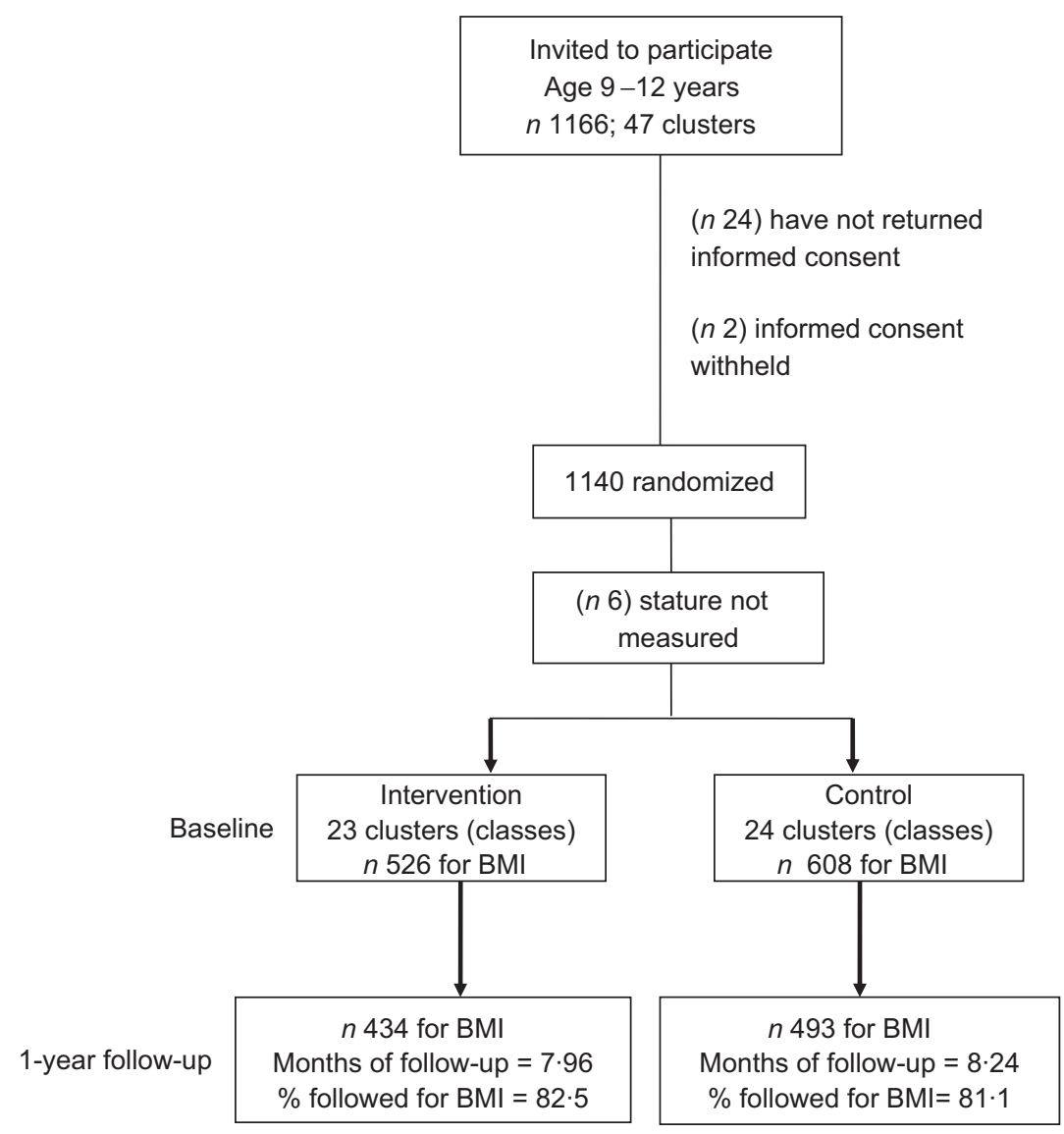

Fig. 1 Progress of students during the study 


\section{Intervention}

The intervention evaluated in the present study focused on the reduction in consumption of sugar-sweetened carbonated beverages by students. During seven months of one school year, a healthy lifestyle education programme was implemented using simple messages encouraging water consumption instead of sugar-sweetened carbonated beverages. The messages were previously tested for understanding in two small groups of children of the same age and socio-economic background as the study participants. Also, beliefs and behaviours of children in these focus groups were recorded in order to orient activities and the production of printed materials to be given to participants. Education was delivered via classroom activities; banners were hung promoting water consumption, and water bottles with the logo of the campaign were given to children and schoolteachers.

All children in the intervention classes were taught the importance of drinking water and asked to make drawings and songs about water and how much the body needs it. The main strategy was to convey the message that drinking water is positive. The body needs water and water should be drunk frequently. A 'pyramid of drinking' was created to communicate the message that water (the basis of the pyramid) should take prevalence over sugarsweetened beverages (at the top of the pyramid). The centre of the campaign was to encourage the exchange of sugar-sweetened beverages for water. Ten one-hour sessions of activities facilitated by four trained research assistants were assigned for each class. The activities required 20-30 min and teachers were encouraged to reiterate the message during their lesson. Classroom quizzes and games using water $v$. sugar-sweetened carbonated beverages as the theme, as well as song and drawing competitions, were promoted. In addition, a musician using a tambourine helped each class to collectively develop songs related to drinking water and reducing the consumption of sugar-sweetened carbonated beverages. This musical activity was conducted during three one-hour sessions. The four research assistants and the musician received printed instructions and orientation on how to facilitate the activities.

The control group received only two one-hour general sessions on health issues and printed general advices regarding healthy diets.

\section{Beverage intake measurement}

Beverage intake was measured through one $24 \mathrm{~h}$ recall at baseline and another at the end of the trial. At baseline, following the $24 \mathrm{~h}$ recall, children were also asked about usual frequency of intake of beverages using a short questionnaire with the previous month as the time frame. The questionnaire included sugar-sweetened carbonated beverages (regular and diet), other sugar-sweetened beverages (regular and diet), milk, 100\% fruit juices (referred from now on simply as fruit juice) and powdered flavoured beverages containing sugar. Only five children reported the consumption of diet drinks.

The $24 \mathrm{~h}$ recall and answers to the short questionnaire were obtained by nutritionists during in-person interviews with the children at school.

\section{Main outcome}

Weight variation was measured by change in mean BMI $\left(\mathrm{BMI}=\right.$ weight $(\mathrm{kg}) /$ height $\left.\left(\mathrm{m}^{2}\right)\right)$. Anthropometric measurements were taken at the beginning and at the end of the school year. Height (without shoes) was measured to the nearest $0 \cdot 1 \mathrm{~cm}$ using a portable anthropometer. Weight (in light clothing) was measured to the nearest $0 \cdot 1 \mathrm{~kg}$ on portable scales.

\section{Secondary outcomes}

Overweight and obesity, defined using the BMI cutoffs proposed by Cole et al. (2000) ${ }^{(16)}$, was also examined, since some studies have found changes in body mass following intervention only among those overweight at baseline, and mainly among girls ${ }^{(6,8)}$. Underweight was defined based on WHO (1995) criteria $^{(17)}$.

\section{Data analysis}

Data from $24 \mathrm{~h}$ recall were computed for all beverages and total added sugar. Schools serve two meals daily for free: breakfast and lunch. The meals are the same for every student, which makes it easy for recording purposes, since children need to only report the portions they consumed. Following the interview by the nutritionist, the reports of items eaten at or out of school were reviewed for adequate description, preparation and their portions. A software containing usual portion sizes developed for analysing Brazilian dietary intake data was used, Programa de Apoio a Nutriçao - NutWin version $2 \cdot 0$ (Departamento de Informática em Saúde, Universidade Federal de Sao Paulo, Brazil).

Regarding the short-frequency questionnaire, the total frequency of intake was estimated using frequency values that ranged from 'zero' to 'three per day.' The questionnaire includes seven exclusive categories, raging from '3 or more per day' to 'never or almost never.'

\section{Statistical analysis}

Baseline characteristics of the two groups were compared using either the Student's $t$ test or the $\chi^{2}$ test. Data on those students who completed the study were compared (baseline $v$, after intervention) using paired $t$-tests. Intention-to-treat analysis was also performed using longitudinal analysis taking into account the cluster (classes) effect through mixed models ${ }^{(18)}$. Data were analysed using SAS, version $8 \cdot 2$ (SAS Institute Inc., Cary, NC, USA). Two analyses were conducted: (i) change in BMI, therefore only data on completers were included; and (ii) modelling the change of BMI using all data. BMI was logtransformed because BMI distribution was skewed to the 
right. Correlation between the intake of juices and beverages and the intake of added sugars based on $24 \mathrm{~h}$ recall was calculated through the Spearman correlation coefficient.

Individuals were the unit of analysis for anthropometric variables. However, for changes in beverage consumption, the mean beverage intake of classes was used instead of individual data since $24 \mathrm{~h}$ is a good estimate for a group but not for individuals.

\section{Results}

Consent was given by most of the parents. Only twenty-six students refused or did not return the informed consent. Loss to follow-up added up to $18 \%$. Children out of the age range of between 9 and 12 years were allowed to participate but they did not contribute data. The mean follow-up time was slightly greater in the control group (8.24 months $v .7 .96$ months; $P$ value $=0.02)$ and the percentage of students followed was slightly greater in the intervention group (82.5\% v. $81 \cdot 1 \%$ in the control group) (Fig. 1). A large number of children participated in the trial, but some of them did not agree to be interviewed for the $24 \mathrm{~h}$ recall at baseline and at the end of the study, with $85 \%$ answering the $24 \mathrm{~h}$ recall at baseline, and $86 \%$ of those followed also answered the $24 \mathrm{~h}$ recall at the end of the study. Anthropometric indices between those students with follow-up data on intake compared with those who refused to participate were similar for BMI $\left(18 \cdot 1 v \cdot 18 \cdot 3 \mathrm{~kg} / \mathrm{m}^{2} ; t\right.$ test $P$ value $\left.=0 \cdot 43\right)$.
Groups were similar at baseline for age, sex, race, anthropometric measurements and beverage intake (Table 1a). The intracluster correlation coefficient for BMI was $0 \cdot 024$. At baseline, the intake of sugar-sweetened beverages was reported by $53 \%$ of participants in the $24 \mathrm{~h}$ recall. The mean amount of carbonated beverages reported was $547 \mathrm{ml}$, which was greater than the amount of juices reported, which varied from $388 \mathrm{ml}$ for powdered juice to $404 \mathrm{ml}$ for fresh or concentrated juice (Table 1b).

Twenty-five students reported drinking juices and powdered flavoured beverages only, and 224 reported in the $24 \mathrm{~h}$ recall drinking both sugar-sweetened beverages and juices. The correlation coefficient between added sugar, for those 651 students reporting sugar intake in the previous day, was $0.34(P<0 \cdot 0001)$ with the amount of juice/powdered flavoured beverages intake, and $-0 \cdot 15$ $(P<0 \cdot 0001)$ with amount of carbonated beverages intake.

The questionnaire regarding the usual intake of beverages in the previous month indicated that $98.8 \%$ drink sugar-sweetened beverages with a daily intake frequency of $0 \cdot 62$.

At the end of the study, BMI and weight had increased in both groups and the mean intake of sodas per class was reduced in both groups, with reduction being about four times greater in the intervention compared with the control group $(-69 \mathrm{ml} v .-13 \mathrm{ml}$ ) (Table 2). The overall change in the BMI was not statistically significant between the two groups even after adjusting for age and time of follow-up. However, among those students overweight at

Table 1 Baseline data: (a) intervention and control group data. (b) number $(n)$ and percentage of students (\%) reporting beverage intake, and means and SE of selected drinks and sugar added to beverages, among those 968 who answered the $24 \mathrm{~h}$ recall

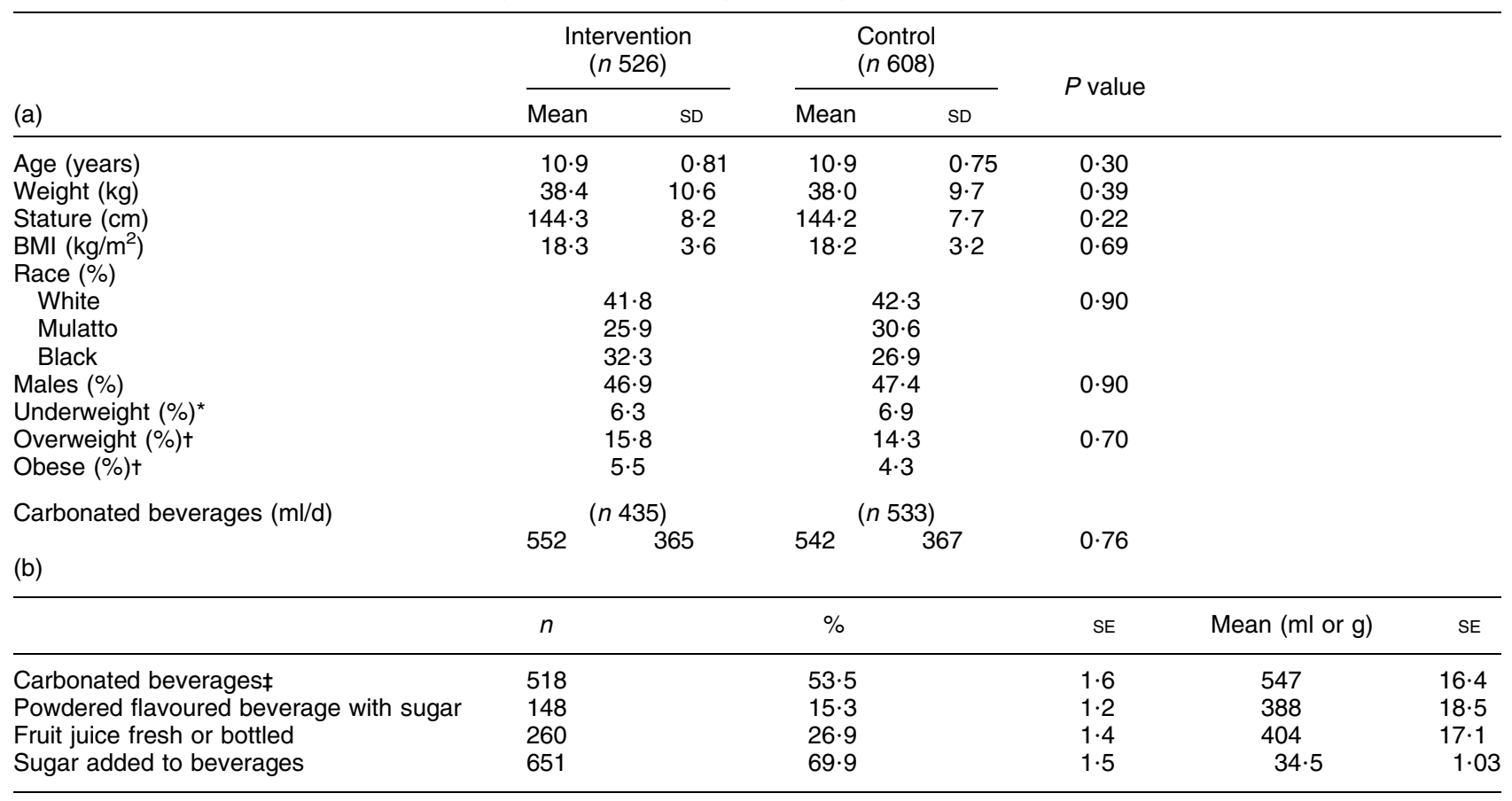

${ }^{*}$ WHO $(1995)^{(17)}$.

tCole et al. $(2000)^{(16)}$.

‡Only five students reported consumption of diet or light beverages. 
Table 2 Mean change in weight, BMI and intake of sodas and $95 \% \mathrm{Cl}$ in the intervention and control groups, from baseline to the end of the school year for completers

\begin{tabular}{|c|c|c|c|c|c|c|}
\hline & \multicolumn{2}{|c|}{$\begin{array}{l}\text { Intervention } \\
\text { ( } n \text { 434) }\end{array}$} & \multicolumn{2}{|c|}{$\begin{array}{l}\text { Control } \\
(n \text { 493) }\end{array}$} & \multicolumn{2}{|c|}{ Intervention-control } \\
\hline & Mean & $95 \% \mathrm{Cl}$ & Mean & $95 \% \mathrm{Cl}$ & Mean & $95 \% \mathrm{Cl}$ \\
\hline Weight (kg) & $2 \cdot 8$ & $2 \cdot 5,3 \cdot 2$ & $2 \cdot 8$ & $2 \cdot 6,3 \cdot 0$ & -0.00009 & $-0 \cdot 40,0.40$ \\
\hline BMI $\left(\mathrm{kg} / \mathrm{m}^{2}\right)$ & $0 \cdot 32$ & $0 \cdot 19,0.46$ & $0 \cdot 22$ & $0.13,0.32$ & $0 \cdot 10$ & $-0.06,0 \cdot 10$ \\
\hline Carbonated beverages $(\mathrm{ml} / \mathrm{d})$ per class & $-69 \cdot 0$ & $-114 \cdot 0,-24 \cdot 0$ & $-13 \cdot 0$ & $-56 \cdot 0,31 \cdot 0$ & $-56 \cdot 0$ & $-119 \cdot 0,-7 \cdot 0$ \\
\hline
\end{tabular}

Table 3 Change in BMI $\left(\mathrm{kg} / \mathrm{m}^{2}\right)$ according to intervention, adjusted for other age and follow-up

\begin{tabular}{|c|c|c|}
\hline & Regression coefficient ${ }^{*}$ & $P$ value \\
\hline \multicolumn{3}{|l|}{ All participants } \\
\hline Intervention/control (log BMI) & -0.003 & $0 \cdot 33$ \\
\hline Age (years) & 0.015 & 0.002 \\
\hline Months of follow-up & -0.001 & 0.39 \\
\hline \multicolumn{3}{|l|}{ Overweight at baseline } \\
\hline Intervention/control (log BMI) & -0.007 & $0 \cdot 11$ \\
\hline \multicolumn{3}{|l|}{ Girls-overweight at baseline } \\
\hline Intervention/control (log BMI) & -0.01 & 0.009 \\
\hline
\end{tabular}

${ }^{*}$ Proc mixed models taking into account the cluster effect.

baseline, the intervention group showed greater BMI reduction, and this difference was statistically significant among girls ( $P=0 \cdot 009$; Table 3$)$.

For both groups, obesity changed from about 4 to $4 \cdot 5 \%$ (Table 4). Carbonated beverage intake was significantly reduced in the intervention group compared with the control group, but fruit juice consumption was slightly increased in the intervention group $(P=0 \cdot 08)$; for those who had not reported intake it was assumed to be zero (Table 4).

\section{Discussion}

Soda intake has grown more than $400 \%$ in the last three decades in Brazil ${ }^{(19)}$, and now there are many low-cost brands of soda available for the low-income population. We anticipated that this scenario would be adequate to test the hypothesis that the discouragement of intake of carbonated beverages would prevent excessive weight gain, but this single message was not effective in reducing excessive weight gain. However, we found a statistically significant decrease in BMI among overweight or obese girls at baseline, even though their sample size was small. Other studies have shown that gender and baseline BMI may explain better the changes in body weight associated with sugar-sweetened beverages ${ }^{(20)}$.

Overall baseline intake of carbonated drinks in the English study was slightly greater (approximately two glasses per day), whereas the mean baseline daily intake in our study was one and a half glasses, and $50 \%$ of the students at baseline in our trial did not drink carbonated beverages.

We anticipated a reduction of consumption of half a glass of sodas per student per day, but our results showed
Table 4 Prevalence (\%) of overweight and obesity ${ }^{*}$ according to intervention and mean intake of beverages in $\mathrm{ml}$ for those completing the study

\begin{tabular}{|c|c|c|c|}
\hline & $\begin{array}{l}\text { Baseline } \\
(\%)\end{array}$ & $\begin{array}{l}\text { End of the study } \\
(\%)\end{array}$ & $P$ valuet \\
\hline \multicolumn{4}{|l|}{ Overweight } \\
\hline Intervention & $16 \cdot 2$ & $19 \cdot 2$ & \multirow[t]{2}{*}{$0 \cdot 13$} \\
\hline Control & $13 \cdot 9$ & $16 \cdot 0$ & \\
\hline \multicolumn{4}{|l|}{ Obesity } \\
\hline Intervention & $4 \cdot 06$ & $4 \cdot 4$ & \multirow[t]{2}{*}{0.95} \\
\hline \multirow[t]{2}{*}{ Control } & $4 \cdot 10$ & $4 \cdot 5$ & \\
\hline & Mean & Mean & \\
\hline \multicolumn{4}{|c|}{$\begin{array}{l}\text { Daily intake of carbonated } \\
\text { beverages (ml) } \ddagger\end{array}$} \\
\hline Intervention & 295 & 228 & \multirow[t]{2}{*}{0.03} \\
\hline Control & 292 & 280 & \\
\hline \multicolumn{4}{|c|}{ Daily intake of juices (ml) } \\
\hline Intervention & 146 & 151 & \multirow[t]{2}{*}{0.08} \\
\hline Control & 103 & 115 & \\
\hline
\end{tabular}

${ }^{*}$ Cole et al. $(2000)^{(16)}$

$+\chi^{2}$ or $t$ test at the end of the study.

fFor those not reporting intake, value was set 0 .

a statistically significant reduction in soda intake of $66 \mathrm{ml}$ in the intervention group compared with the control group ( 0.25 glasses). However, because of the large sample size in our study, this small change may have contributed to the overall negative findings. Also, the small self-reported change, representing about a $10 \%$ reduction of baseline intake, was associated with compensation due to an increase in juices. The changes in consumption indicate that future interventions should allow exchanges to low sugar products, instead of a too big switch such as, in this case, to plain water.

A limitation in the study was the use of one $24 \mathrm{~h}$ recall, which is not the best method to measure intake. During the pre-test, a $3 \mathrm{~d}$ diary was used, but most children did not return them or brought them with highly incomplete data. Nevertheless, one $24 \mathrm{~h}$ recall provides a good estimation of group intake (classes) ${ }^{(21)}$. Also, at baseline, the usual frequency of beverage intake measured by a frequency questionnaire indicated that $98 \%$ of students drink sodas with a daily frequency of 0.62 , a value that is close to the $53 \%$ reported use in the previous day, measured by the $24 \mathrm{~h}$ recall.

The negative finding of the study may also be due to slight family involvement. Meeting with the parents was attempted at the beginning of the study without success, so we only 
sent them fliers and a fridge magnet to remind them of cutting down on carbonated beverages. Also, the intervention may not have been sufficiently intense or long enough to change behaviour. In addition, the reduction in drinking sugar-sweetened carbonated beverages as reported by students was combined with an increase in juice intake, which suggests that juices may have blurred the effects of soda reduction. A trend of substitution of sodas by juices or flavoured beverages has been observed in the USA ${ }^{(22)}$. Powdered fruit-flavoured drinks are very inexpensive in Brazil, and our data showed that the amount of sugar added per day in these beverages is greater than the amount of sugar in one glass of soda. The mean of sugar added was $34.5 \mathrm{~g} / \mathrm{d}$, whereas $250 \mathrm{ml}$ of soda has $26 \mathrm{~g}$ of sugar.

Although the results from a systematic review indicate that regular sugar-sweetened beverage consumption is associated with weight gain ${ }^{(13)}$, in a large national survey - UK National Dietary and Nutritional Survey of Young People - using weighed $7 \mathrm{~d}$ food records, the risk associated with caloric soft drinks was non-linear with an increased risk only for very high consumers ${ }^{(20)}$, not frequent in our population.

Strategies of primary prevention of obesity that may prove effective, mainly among low socio-economic groups, are desperately needed and may be mandatory in developing countries given the burden associated with chronic diseases related to obesity. Unfortunately, the single message of cutting down on sodas was effective only among overweight girls, suggesting that efforts to reduce energy intake though liquids should also emphasise overall sweetened beverages, including the addition of sugar to juices.

\section{Acknowledgements}

Funding support: The study was supported by the Brazilian National Research Council - CNPq. Grant number: 500404/2003-8 - CNPq.

Conflict of interest: None.

Authors' contributions: R.S. was the principal investigator, led the research project and participated in all phases of the study. G.V.V. was a co-investigator of the project and participated in conceptualisation of the intervention and collaborated in the manuscript. A.P.T. and R.A.S. conducted the analysis and collaborated in the manuscript.

Acknowledgements: We thank Walter Willett for helpful comments in the project and manuscript, and Fernanda Albuquerque Melo Nogueira, Flavia de Andrade Borges and Maria Eliza Mattos T. Mastrangelo for helping in the intervention and data collection.

\section{References}

1. Basset MT \& Perl S (2004) Obesity: the public health challenge of our time. Am J Public Health 94, 1477.

2. Monteiro CA, Conde WL \& Popkin BM (2004) The burden of disease from undernutrition and overnutrition in countries undergoing rapid nutrition transition: a view from Brazil. Am J Public Health 94, 433-434.

3. Veiga GV, da Cunha AS \& Sichieri R (2004) Trends in overweight among adolescents living in the poorest and richest regions of Brazil. Am J Public Health 94, 1544-1548.

4. Warren JM, Henry CJ, Lightowler HJ, Bradshaw SM \& Perwaiz S (2003) Evaluation of a pilot school programme aimed at the prevention of obesity in children. Health Promot Int 18, 287-296.

5. Atkinson RL \& Nitzke SA (2001) School based programmes on obesity. BMJ 323, 1018-1019.

6. Gortmaker SL, Peterson K, Wiecha J, Sobol AM, Dixit S, Fox MK \& Laird N (1999) Reducing obesity via a school-based interdisciplinary intervention among youth: Planet Health. Arch Pediatr Adolesc Med 153, 409-418.

7. Stice H, Shaw H \& Marti N (2006) A meta-analytic review of obesity prevention programs for children and adolescents: the skinny on interventions that work. Psychol Bull 132, 667-691.

8. Katz DL, O'Connell M, Njike VY, Yeh MC \& Nawaz H (2007) Strategies for the prevention and control of obesity in school setting: systematic review and meta-analysis. Int J Obes (Lond) (Epublication ahead of print version).

9. James J, Thomas P, Cavan D \& Kerr D (2004) Preventing childhood obesity by reducing consumption of carbonated drinks: cluster randomised controlled trial. BMJ 328, 1237-1241.

10. Ludwig DS, Peterson KE \& Gortmaker SL (2001) Relation between consumption of sugar-sweetened drinks and childhood obesity: a prospective, observational analysis. Lancet 357, 505-508.

11. Berkey CS, Rockett HR, Field AE, Gillman MW \& Colditz GA (2004) Sugar-added beverages and adolescent weight change. Obes Res 12, 778-788.

12. Striegel-Moore RH, Thompson D, Affenito SG et al. (2006) Correlates of beverage intake in adolescent girls: the National Heart, Lung, and Blood Institute Growth and Health Study. J Pediatr 148, 183-187.

13. Malik VS, Schulze MB \& Hu FB (2006) Intake of sugarsweetened beverages and weight gain: a systematic review. Am J Clin Nutr 84, 274-288.

14. Sutton A (2004) Childhood obesity and consumption of fizzy drinks: play outside to reduce childhood obesity. BMJ 329, 51-54.

15. Story M, Kaphingst KM \& French S (2006) The role of schools in obesity prevention. http://www.futureofchildren. org/information28269 (accessed October 2007).

16. Cole TJ, Bellizzi MC, Flegal KM \& Dietz WD (2000) Establishing a standard definition for child overweight and obesity worldwide: international survey. BMJ 320, 1-6.

17. World Health Organization, Expert Committee (1995) Physical Status: The Use and Interpretation of Anthropometry. Technical Report Series no. 854. Geneva: WHO.

18. Singer JD \& Willett JB (2003) Applied Longitudinal Data Analysis - Modeling Change and Event Occurrence. New York: Oxford University Press.

19. Levy-Costa RB, Sichieri R, Pontes NS \& Monteiro CA (2005) Household food availability in Brazil: distribution and trends (1974-2003). Rev Saúde Pública 39, 530-540.

20. Gibson S \& Neate D (2007) Sugar intake, soft drink consumption and body weight among British children: further analysis of National Diet and Nutrition Survey data with adjustment for under-reporting and physical activity. Int J Food Sci Nutr 58, 445-460.

21. Buzzard M (1998) 24 hour dietary recall and food record methods. In Nutritional Epidemiology, pp. 50-73 [W Willett, editor]. New York, NY: Oxford University Press.

22. Cavadini C, Siega-Riz AM \& Popkin BM (2000) US adolescent food intake trends from 1965 to 1996. Arch Dis Child 83, 18-24. 